\title{
Mechanism of Anterior Cruciate Ligament Injury in Female Soccer
}

\section{Players}

\author{
Satoshi Kaneko, ${ }^{1,}$ Shogo Sasaki, ${ }^{2}$ Norikazu Hirose, ${ }^{3}$ Yasuharu Nagano, ${ }^{4}$ Mako Fukano, ${ }^{3}$ and Toru \\ Fukubayashi ${ }^{3}$ \\ ${ }^{1}$ Graduate School of Sport Sciences, Waseda University, Saitama, Japan \\ ${ }^{2}$ Tokyo Ariake University of Medical and Health Sciences, Tokyo, Japan \\ ${ }^{3}$ Faculty of Sport Sciences, Waseda University, Saitama, Japan \\ ${ }^{4}$ Department of Sports Wellness Sciences, Japan Women's College of Physical Education, Tokyo, Japan \\ "Corresponding author: Satoshi Kaneko, Graduate School of Sport Sciences, Waseda University, 2-579-15 Mikashima, Tokorozawa-shi, Saitama 359-1192, Japan. Tel: +81-429476848, \\ Fax: +81-429476801, E-mail: kaneko.3104@gmail.com
}

Received 2016 April 19; Revised 2016 August 15; Accepted 2016 September 24.

\begin{abstract}
Background: The risk of anterior cruciate ligament (ACL) injury is higher in female soccer players than in male soccer players. The most common reason for non-contact ACL injury has been found to be a cutting or stopping maneuver combined with deceleration and landing from a jump. In a previous study, there was no difference in the incidence of ACL injury between offensive and defensive players and in the risk of ACL injury between goalkeepers and other players. Recently studies reported that the most frequent injury situation was pressing in male players. However, the most common type of situation associated with ACL injury in female soccer players has not been clarified.

Objectives: The purpose of the present study was to identify the most common type of situation associated with ACL injury in female soccer players.

Methods: We handed out questionnaires to 80 female soccer players with a history of ACL injury (90 ACL injuries). The players were asked about the injury characteristics, injury circumstance, maneuver being performed when the injury occurred, and playing type associated with the injury. The players responded to the questionnaire under the guidance of the medical staff of each team.

Results: The 80 female soccer players reported a total of 90 ACL injuries during soccer. Among 55 non-contact injuries, 29 (55\%) occurred during a cutting maneuver and 22 (44\%) occurred during pressing. On assessing the frequency distributions of playing type (pressing vs. others) and body contact (contact vs. no contact), we found that non-contact injuries at pressing were significantly more common than contact injuries at pressing (odds ratio: 3.03; 95\% confidence interval, $1.11-8.25, \mathrm{P}=0.036$ )

Conclusions: ACL injury often occurs as non-contact injury during pressing at the time of defense, regardless of the playing area, in female soccer players.
\end{abstract}

Keywords: Anterior Cruciate Ligament Injury, Soccer, Female, Pressing

\section{Background}

Soccer is considered the most popular sport worldwide, with more than 265 million active players, and it has been found that the proportion of female players is notably increasing, with female players accounting for $10 \%$ of all active players (1). Additionally, the risk of anterior cruciate ligament (ACL) injury has been reported to be up to six times higher in female players than in male players (2).

Non-contact ACL injuries have been reported to account for $70 \%-84 \%$ of ACL injuries in athletes (3-5). These injuries mainly result from a cutting or stopping maneuver combined with deceleration and landing from a jump $(4,6)$. The alignment associated with a non-contact ACL injury occurs during a deceleration task with the body weight shifted over to the injured leg and the plantar surface of the foot fixed flat on the ground (6-9). The knee alignment associated with non-contact ACL injury involves lower flexion, valgus, and internal rotation (10).

In a previous study, there was no difference in the incidence of ACL injury between offensive and defensive soccer players (4). Additionally, this previous study found that there was no difference in the risk of ACL injury between goalkeepers and other players, although the ball contact time was lower for goalkeepers than for other players (4). In professional soccer players, the most frequent injury situation was pressing, which involves cutting and stopping with one leg while trying to steal the ball with the other leg (11).

However, the abovementioned previous studies focused on male soccer players, although the risk of ACL injury has been shown to be 4 - 6 times higher in female athletes than in male athletes (12). A previous study has shown

Copyright (c) 2016, Sports Medicine Research Center. This is an open-access article distributed under the terms of the Creative Commons Attribution-NonCommercial 4.0 International License (http://creativecommons.org/licenses/by-nc/4.0/) which permits copy and redistribute the material just in noncommercial usages, provided the original work is properly cited. 
that the relative risk of ACL injury was nine times higher in female soccer players than in male soccer players (13). The most common type of situation associated with ACL injury in female soccer players has not been clarified.

\section{Objectives}

The purpose of the present study was to identify the most common type of situation associated with ACL injury in female soccer players. We hypothesized that ACL injury often occurs as non-contact injury during a cutting or stopping maneuver (pressing) at the time of defense.

\section{Methods}

This was a descriptive report. Among 518 female soccer players in 15 teams (11 university teams and 4 club youth teams under the Japan Football Association), we handed out questionnaires to 80 female soccer players with a history of ACL injury. The 80 female soccer players reported a total of 90 ACL injuries during soccer, which included fresh, recurrent, and bilateral injuries. All participants and, if necessary, their parents received an explanation of this study, and informed consent was obtained before this study began.

The players were asked about the injury characteristics, injury circumstance, maneuver being performed when the injury occurred, and playing type associated with the injury. Additionally, they were asked about the location on the soccer field where the injury occurred. The players responded to the questionnaire after recalling the injury situation under the guidance of the medical staff of each team. The questionnaire collected data on the following variables: 1) age, 2) dominant leg, 3) side of the injured knee, 4) type of surface, 5) type of spikes, 6) position, 7) involvement of body contact, 8) game or practice, 9) playing area, 10) offense or defense, 11) involvement of the ball, 12) playing type (dribbling, passing, trapping, shooting, heading, sliding, clearing, pressing, or loose ball, and goalkeeper or other player),13) manoeuver, and 14) playing intensity (Figure 1).

Body contact was classified as "no contact," "indirect contact" (contact at any body region other than the injured leg), or "direct contact" (contact at the lower limb). Practice games were included in the assessment. As shown in Figure 1, the field was divided into the following zones: the attacking zone (front one-third of the field; areas 1, 2, and 3 ), midfield zone 2 (second half of the middle one-third of the field; areas 4 and 5), midfield zone 1 (first half of the middle one-third of the field; areas 6 and 7), and defensive zone (back one-third of the field; areas 8 and 9) (14).
All data are expressed as mean \pm standard deviation (SD). To clarify the frequency distributions of playing type (pressing vs. others) and body contact (contact vs. no contact), Fisher's exact test was used, and odds ratios (ORs) with $95 \%$ confidence intervals (95\%CIs) were calculated. All statistical analyses were performed using SPSS version 20.0 (IBM Corp., Armonk, NY). A P-value < 0.05 was considered significant.

The ethics committee of our institution approved this research.

\section{Results}

The present study assessed a total of 90 ACL injuries among female soccer players who responded to the ACL questionnaire. The mean age of the players was $19.4 \pm 2.3$ years, and the mean age at injury was $17.4 \pm 1.9$ years. The highest number of injuries occurred at the age of 18 years (Figure 2). Among the 90 injuries, 62 (69\%) occurred on artificial turf, 57 (63\%) occurred in players wearing round spikes, 41 (46\%) occurred in defenders, 54 (60\%) occurred during defense, 56 (62\%) occurred during a game, and 55 (61\%) were non-contact injuries (Table 1).

Table 1. Characteristics and Circumstances During Anterior Cruciate Ligament Injuries

\begin{tabular}{lc}
\hline Characteristics and Circumstances & Total $(\mathbf{n}=\mathbf{9 0})$ \\
\hline Dominant leg/Non-dominant leg & $48 / 42$ \\
\hline Natural turf/Artificial turf/Soil & $16 / 62 / 12$ \\
\hline Round-type spikes/Blade-type spikes/Unknown & $57 / 32 / 1$ \\
\hline GK/DF/MF/FW & $7 / 41 / 26 / 16$ \\
\hline Offense/Defense & $36 / 54$ \\
\hline Game/Practice & $56 / 34$ \\
\hline Lower contact/Upper contact/Non-contact & $21 / 14 / 55$ \\
\hline
\end{tabular}

Abbreviations: DF, defender; FW, forward; GK, goalkeeper; MF, midfielder.

Among the 55 non-contact injuries, 29 (55\%) occurred during a cutting maneuver and 22 (44\%) occurred during pressing (Table 2). On assessing the frequency distributions of playing type (pressing vs. others) and body contact (contact vs. no contact), we found that non-contact injuries at pressing were significantly more common than contact injuries at pressing (OR: 3.03; 95\%CI, 1.11 - 8.25, P = 0.036 ) (Figure 3). Of the 35 (63\%) injuries that occurred during defense in the game, 16 (46\%) occurred in the defensive zone. Additionally, of the 16 (46\%) injuries that occurred at pressing, 4 (25\%) occurred in the defensive zone. 
Figure 1. Questionnaire on the Circumstances of Anterior Cruciate Ligament Injury

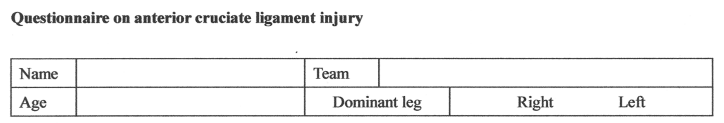

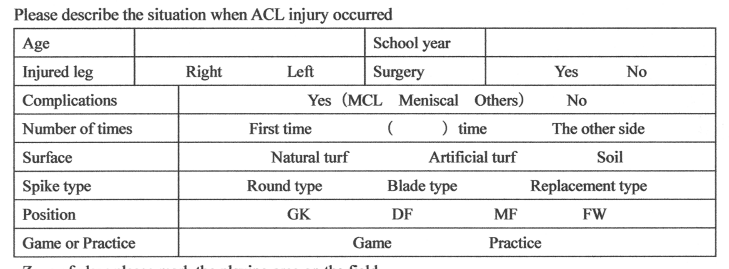

Zone of play: please mark the playing area on the field.

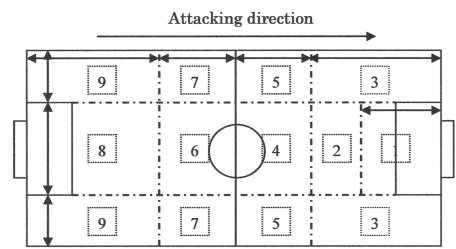

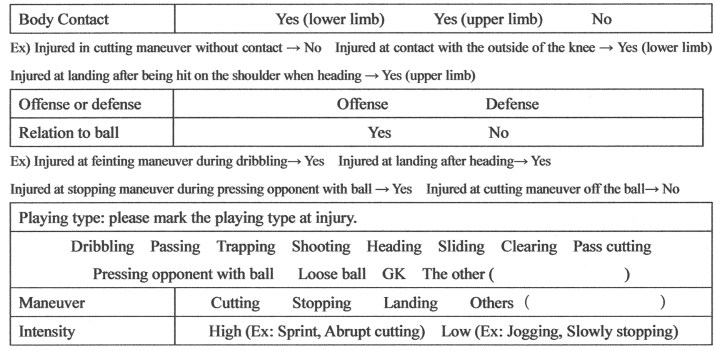

Please provide information on other things that you remember.

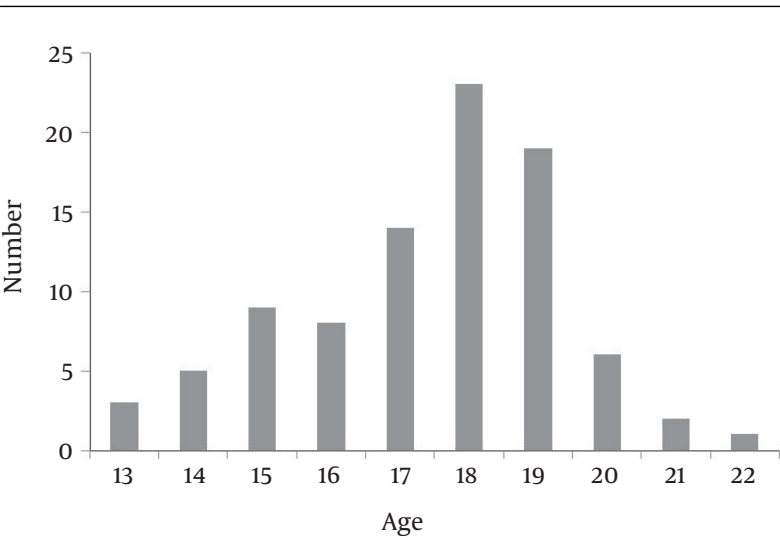

Figure 2. Age at Anterior Cruciate Ligament Injury

\section{Discussion}

The present study found that ACL injury often occurs as non-contact injury during pressing at the time of defense, Asian J Sports Med. 2017; 8(1):e38205.

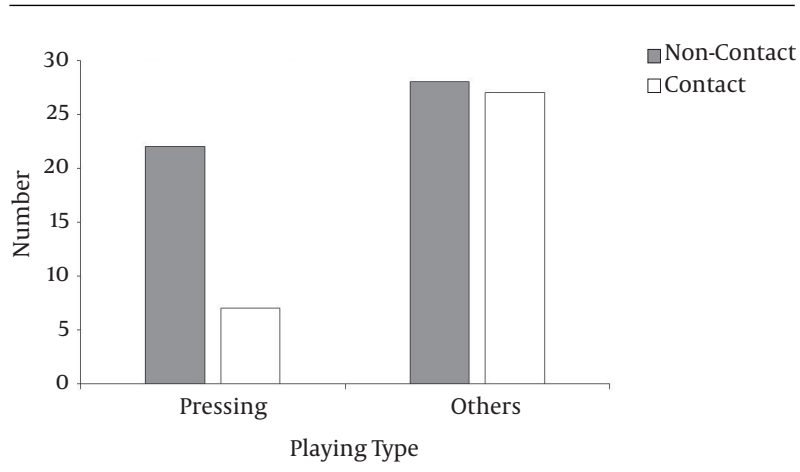

Figure 3. Playing Type at Anterior Cruciate Ligament Injury

regardless of the playing area, in female soccer players.

In the present study, the female soccer players had a higher risk of sustaining non-contact ACL injuries than 
Table 2. Playing Type, Playing Situation, and Maneuver During Anterior Cruciate Ligament Injuries

\begin{tabular}{|c|c|c|c|c|}
\hline & Playing Type & Playing Situation & Player Contact & Maneuver at Non-Contact Injury \\
\hline \multirow{3}{*}{ Pressing $(n=29)$} & \multirow{3}{*}{ Pressing to opponent $(n=29)$} & Defense $(n=29)$ & Non-contact $(\mathrm{n}=22)$ & Cutting $(\mathrm{n}=17)$ \\
\hline & & & Indirect $(\mathrm{n}=3)$ & Stopping $(n=5)$ \\
\hline & & & $\operatorname{Direct}(n=4)$ & \\
\hline \multirow{3}{*}{ Dribbling $(n=14)$} & \multirow{3}{*}{$\operatorname{Dribbling}(\mathrm{n}=14)$} & Offense $(n=14)$ & Non-contact $(n=6)$ & Cutting $(\mathrm{n}=5)$ \\
\hline & & & Indirect $(\mathrm{n}=3)$ & The other $(\mathrm{n}=1)$ \\
\hline & & & $\operatorname{Direct}(\mathrm{n}=5)$ & \\
\hline \multirow{3}{*}{$\operatorname{Trapping}(\mathbf{n}=\mathbf{1 1})$} & \multirow{3}{*}{ Trapping $(\mathrm{n}=11)$} & Offense $(n=10)$ & Non-contact $(\mathrm{n}=3)$ & Stopping $(\mathrm{n}=1)$ \\
\hline & & Defense $(n=1)$ & Indirect $(\mathrm{n}=2)$ & Landing $(\mathrm{n}=2)$ \\
\hline & & & $\operatorname{Direct}(n=6)$ & \\
\hline \multirow{2}{*}{ Loose ball $(n=6)$} & \multirow{2}{*}{ Competing for loose ball $(n=6)$} & Offense $(\mathrm{n}=2)$ & Non-contact $(\mathrm{n}=2)$ & Landing $(\mathrm{n}=1)$ \\
\hline & & Defense $(n=4)$ & $\operatorname{Direct}(n=4)$ & The other $(\mathrm{n}=1)$ \\
\hline \multirow{3}{*}{ Kicking $(\mathbf{n}=9)$} & Shooting $(n=4)$ & Offense $(\mathrm{n}=8)$ & Non-contact $(\mathrm{n}=7)$ & Landing $(\mathrm{n}=2)$ \\
\hline & Passing $(n=4)$ & Defense $(n=1)$ & Indirect $(\mathrm{n}=1)$ & The other $(n=5)$ \\
\hline & Clearing $(\mathrm{n}=1)$ & & $\operatorname{Direct}(\mathrm{n}=1)$ & \\
\hline \multirow{5}{*}{ Others $(n=15)$} & Pass cutting $(n=4)$ & Offense $(\mathrm{n}=2)$ & Non-contact $(n=9)$ & Cutting $(\mathrm{n}=2)$ \\
\hline & $\mathrm{GK}(\mathrm{n}=4)$ & Defense $(n=12)$ & Indirect $(\mathrm{n}=3)$ & Stopping $(\mathrm{n}=1)$ \\
\hline & Heading $(\mathrm{n}=3)$ & & $\operatorname{Direct}(\mathrm{n}=2)$ & Landing $(\mathrm{n}=7)$ \\
\hline & Sliding $(\mathrm{n}=2)$ & & & \\
\hline & Others $(n=2)$ & & & \\
\hline
\end{tabular}

Abbreviation: GK, goalkeeper.

contact injuries, which is consistent with the findings of previous studies (3-5). Additionally, non-contact ACL injuries occurred more often during pressing (76\%) than during other playing movements (49\%), such as dribbling, trapping, and kicking. This is consistent with the finding of a previous study that reported a high incidence of ACL injury during pressing in professional male soccer players (11). In addition, this study reported that the maneuver performed in the injured players was side cutting on one leg while extending one leg towards the ball during pressing. Excessive hip internal rotation and knee internal rotation will be present during this cutting maneuver, and these have been identified as risk factors for non-contact ACL injury (15). Moreover, the greater knee abduction (valgus) angle in female athletes than in male athletes is associated with a higher risk of non-contact ACL injury in female athletes $(16,17)$. We found that ACL injuries occurred more frequently during defensive actions than during attacking actions. ACL injuries during defense occurred in the defensive one-third of the field. However ACL injuries during pressing occurred throughout the playing area. A previous study reported that most incidents during defense occurred in the defensive one-third of the field, whereas most incidents during offense occurred in the attacking one-third of the field (14). Whether pressing has been conducted in any area depends on the tactics of the team, and it should be confirmed that the pressing maneuver during defensive actions is associated with a high risk of sustaining non-contact ACL injuries in female soccer players.

In the present study, ACL injury was the most common at the age of 18 years. In addition, the incidence of ACL injury increased up to the age of 18 years and then reduced from the age of 20 years. A previous study reported that the incidence of ACL injury in female subjects was the highest at 15 - 19 years of age (18), which is consistent with our finding. Another study reported that knee movement increases with a rapid increase in body height and weight (19), which is caused by exponential growth during puberty. Dynamic alignment in the jump task during puberty has been reported to change with physical growth (20). These changes have been shown to be associated with various factors, such as anatomical, environmental, hormonal, neuromuscular, and biomechanical factors (21). Therefore, training focused on correcting dynamic alignment is es- 
sential in young female soccer players, especially those aged $<18$ years.

The incidence of ACL injury was very high on artificial turf. A previous study reported a high rate of ACL injury on synthetic playing surfaces in football, but did not find an increase in the risk of ACL injury on synthetic playing surfaces in soccer (22). In Japan, young female soccer players rarely play on natural grass. Therefore, the number of games played might have influenced the result, and it cannot be concluded that artificial turf increases the risk of serious ACL injury. In this study, the incidence of ACL injury was high in players who used round spikes. A previous study reported that foot mechanics and possibly the foot-shoe interaction were not related to the landing mechanics in female soccer players (23). In order to determine whether the use of round spikes can significantly increase the risk of ACL injury, it would be required to ascertain the type of spikes used by players of all the teams.

The present study found that ACL injury in female players occurred more often during a game than during practice, and this might be because a player's momentum and intensity are higher during a game than during practice. In addition, there is a high possibility of ACL injury during a game, as the player might have difficulty controlling posture in a confrontation with an opponent.

In the future, movements, such as cutting on one leg while extending one leg to the ball during pressing with a high strength instantaneous reaction, should be practiced to avoid injury during a competition in addition to basic injury prevention methods, which have been adopted until now.

The present study had some limitations. First, this was a retrospective study. Second, the study relied on player recall of the injury for information. In the future, it is necessary to determine the circumstances during ACL injury using videotapes.

\subsection{Conclusions}

ACL injury might often occur as non-contact injury during pressing at the time of defense, regardless of the playing area, in female soccer players. The present findings will aid in the identification of the causes of anterior cruciate ligament injury in female soccer players and will help in the creation of competition-specific rehabilitation and prevention methods.

\section{References}

1. FIFA Communications Division IS . 270 million people active in football. FIFA Big Count 2006. FIFA website 2007. Available from: http://www.fifa.com/mm/document/fifafacts/bcoffsurv/bigcount. statspackage_7024.pdf.
2. Arendt E, Dick R. Knee injury patterns among men and women in collegiate basketball and soccer. NCAA data and review of literature. Am J Sports Med. 1995;23(6):694-701. [PubMed: 8600737].

3. Boden BP, Torg JS, Knowles SB, Hewett TE. Video analysis of anterior cruciate ligament injury: abnormalities in hip and ankle kinematics. Am J Sports Med. 2009;37(2):252-9. doi: 10.1177/0363546508328107. [PubMed: 19182110].

4. Fauno P, Wulff Jakobsen B. Mechanism of anterior cruciate ligament injuries in soccer. Int J Sports Med. 2006;27(1):75-9. doi:10.1055/s-2005837485. [PubMed: 16388446 ].

5. McNair PJ, Marshall RN, Matheson JA. Important features associated with acute anterior cruciate ligament injury. $N Z$ Med J. 1990;103(901):537-9. [PubMed: 2243642]

6. Boden BP, Dean GS, Feagin JA Jr, Garrett WE Jr. Mechanisms of anterior cruciate ligament injury. Orthopedics. 2000;23(6):573-8. [PubMed: 10875418]

7. Teitz CC. Video analysis of ACL injuries. In: Griffin L. Y. , editor. Prevention of Noncontact ACL Injuries. Rosemont: American Academy of Orthopaedic Surgeons; 2001.

8. Krosshaug T, Nakamae A, Boden BP, Engebretsen L, Smith G, Slauterbeck JR, et al. Mechanisms of anterior cruciate ligament injury in basketball: video analysis of 39 cases. Am J Sports Med. 2007;35(3):359-67. doi: 10.1177/0363546506293899. [PubMed: 17092928].

9. Olsen OE, Myklebust G, Engebretsen L, Bahr R. Injury mechanisms for anterior cruciate ligament injuries in team handball: a systematic video analysis. Am J Sports Med. 2004;32(4):1002-12. [PubMed: 15150050].

10. Koga H, Nakamae A, Shima Y, Iwasa J, Myklebust G, Engebretsen L, et al. Mechanisms for noncontact anterior cruciate ligament injuries: knee joint kinematics in 10 injury situations from female team handball and basketball. Am J Sports Med. 2010;38(11):2218-25. doi: 10.1177/0363546510373570. [PubMed: 20595545].

11. Walden M, Krosshaug T, Bjorneboe J, Andersen TE, Faul O, Hagglund $M$. Three distinct mechanisms predominate in non-contact anterior cruciate ligament injuries in male professional football players: a systematic video analysis of 39 cases. Br J Sports Med. 2015;49(22):1452-60. doi: 10.1136/bjsports-2014-094573. [PubMed: 25907183].

12. Hewett TE. Neuromuscular and hormonal factors associated with knee injuries in female athletes. Strategies for intervention. Sports Med. 2000;29(5):313-27. [PubMed: 10840866].

13. Gwinn DE, Wilckens JH, McDevitt ER, Ross G, Kao TC. The relative incidence of anterior cruciate ligament injury in men and women at the United States Naval Academy. Am J Sports Med. 2000;28(1):98-102. [PubMed: 10653551].

14. Andersen TE, Larsen O, Tenga A, Engebretsen L, Bahr R. Football incident analysis: a new video based method to describe injury mechanisms in professional football. Br J Sports Med. 2003;37(3):226-32. [PubMed: 12782547].

15. Imwalle LE, Myer GD, Ford KR, Hewett TE. Relationship between hip and knee kinematics in athletic women during cutting maneuvers: a possible link to noncontact anterior cruciate ligament injury and prevention. J Strength Cond Res. 2009;23(8):2223-30. doi: 10.1519/JSC.ob013e3181bc1a02. [PubMed: 19826304].

16. Chappell JD, Yu B, Kirkendall DT, Garrett WE. A comparison of knee kinetics between male and female recreational athletes in stop-jump tasks. Am J Sports Med. 2002;30(2):261-7. [PubMed: 11912098].

17. Ford KR, Myer GD, Toms HE, Hewett TE. Gender differences in the kinematics of unanticipated cutting in young athletes. Med Sci Sports Exerc. 2005;37(1):124-9. [PubMed: 15632678].

18. Renstrom P, Ljungqvist A, Arendt E, Beynnon B, Fukubayashi T, Garrett $\mathrm{W}$, et al. Non-contact $\mathrm{ACL}$ injuries in female athletes: an International Olympic Committee current concepts statement. Br J Sports Med. 2008;42(6):394-412. doi: 10.1136/bjsm.2008.048934. [PubMed: 18539658]. 
19. Quatman CE, Ford KR, Myer GD, Hewett TE. Maturation leads to gender differences in landing force and vertical jump performance: a longitudinal study. Am J Sports Med. 2006;34(5):806-13. doi: 10.1177/0363546505281916. [PubMed: 16382009].

20. Sasaki S, Tsuda E, Yamamoto Y, Maeda S, Hayashi Y, Kimura Y, et al. Change with increasing age in control of the lower limbs during jump-landing in adolescents: a 5-year prospective study. $\mathrm{J}$ Orthop Sci. 2013;18(5):774-81. doi: 10.1007/s00776-013-0420-3. [PubMed: 23775465].

21. Alentorn-Geli E, Myer GD, Silvers HJ, Samitier G, Romero D, LazaroHaro C, et al. Prevention of non-contact anterior cruciate ligament injuries in soccer players. Part 1: Mechanisms of injury and underlying risk factors. Knee Surg Sports Traumatol Arthrosc. 2009;17(7):705-29. doi: 10.1007/s00167-009-0813-1. [PubMed: 19452139].

22. Balazs GC, Pavey GJ, Brelin AM, Pickett A, Keblish DJ, Rue JP. Risk of Anterior Cruciate Ligament Injury in Athletes on Synthetic Playing Surfaces: A Systematic Review. Am J Sports Med. 2015;43(7):1798-804. doi: 10.1177/0363546514545864. [PubMed: 25164575].

23. Mitchell LC, Ford KR, Minning S, Myer GD, Mangine RE, Hewett TE. Medial Foot Loading on Ankle and Knee Biomechanics. NAm J Sports Phys Ther. 2008;3(3):133-40. [PubMed: 20379384]. 